\title{
O AGRONEGÓCIO SUCROENERGÉTICO E A PAISAGEM REGIONAL NA MICRORREGIÃO CERES (GO) - DA CANG AO CONTEXTO CANAVIEIRO ATUAL
}

\author{
THE SUGARENERGY AGRIBUSINESS AND THE REGIONAL \\ LANDSCAPE IN THE MICROREGION CERES (GO) - FROM \\ CANG TO THE CURRENT CANAVIEIRO CONTEXT
}

\section{EL AGRONEGOCIO DE CAÑA DE AZÚCAR Y EL PAISAJE REGIONAL EN LA REGIÓN CERES (GO) - DE LA CANG AL CONTEXTO CANAVIEIRO ACTUAL}

\author{
Lara Cristine Gomes Ferreira - Universidade de Brasília - Distrito Federal - Brasília - Brasil \\ laracristineufg@yahoo.com.br
}
Fernando Luiz Araujo Sobrinho - Universidade de Brasília - Brasília - Distrito Federal - Brasil flasobrinho@unb.br

\begin{abstract}
Resumo
0 tema do presente artigo versa sobre a territorialização do agronegócio sucroenergético na microrregião Ceres, Goiás, e como essa complexa atividade acaba por influenciar e dinamizar o campo e a cidade, bem como a região a qual está inserida. Faz-se importante na pesquisa compreender o papel das Colônias Agrícolas Nacionais (CANG), durante a Marcha para o Oeste (década de 1940), até o contexto atual na região, relacionado, sobretudo, à expansão do agronegócio canavieiro. Diante disso, tem-se como objetivo central compreender a territorialização canavieira no estado de Goiás, dando enfoque para a microrregião Ceres, bem como para as transformações ocorridas na paisagem regional dessa microrregião. Para tanto, foram necessárias etapas metodológicas de levantamento teórico-conceitual; realização de trabalhos de campo nos municípios da microrregião de Ceres, para a observação e para fazer entrevistas aos principais atores sociais envolvidos; tabulações, mapeamentos e análise dos dados levantados. Pôde-se inferir com essa pesquisa, que as formas espaciais estabelecidas pela atividade sucroenergética, assim como os efeitos, as desigualdades e os conflitos são materializados na paisagem regional, a qual se alterou rapidamente na microrregião de Ceres, com a expansão do capital canavieiro pós-projeto das Colônias Agrícolas Nacionais.

Palavras-chave: Atividade canavieira, Colônias Agrícolas Nacionais, paisagem regional.
\end{abstract}

\section{Abstract}

The theme of this article is about the territorialization of sugarcane agribusiness in Ceres microregion in Goiás (Brazil), and how this complex activity can influence and make dynamic the countryside and the city, as well as the region where they are located. It is important to understand the role of the National Agricultural Colonies (CANG), during the March to the West (1940s), to the current context in the region, related mainly to the expansion of sugar cane agribusiness. In view of this, the central objective is to understand the sugarcane territorialization in the state of Goiás, focusing on the Ceres microregion, as well as on the transformations that occurred in the regional landscape of this microregion. For that, methodological steps of theoreticalconceptual survey were necessary; fieldwork within the municipalities of Ceres microregion, for observations and interviews with the main social actors involved; tabulations, mappings and analysis of data collected. It was possible to infer from this research that the spatial forms established by the sugar-energy activity, as well as the effects, the inequalities and the conflicts are materialized in the regional landscape, which changed 
rapidly in Ceres microregion, with the expansion of the sugarcane capital after the project of the National Agricultural Colonies.

Keywords: Sugarcane activity, National Agricultural Colony, regional landscape.

\section{Resumen}

El tema de la presente investigación se ocupa de la territorialización del agronegocio de caña de azúcar en la región Ceres, Goiás (Brasil), y de como esa compleja actividad acaba por influenciar y dinamizar el campo y la ciudad, así como la región en la que está insertada. Es importante para la investigación comprender el papel de las Colonias Agrícolas Nacionales (CANG), durante la Marcha hacia el Oeste (década de 1940) hasta el contexto actual, en la región, relacionado, sobre todo, a la expansión del agronegocio cañero. Frente a ello, se tiene como objetivo central comprender la territorialización de la caña de azúcar en el estado de Goiás, centrándonos en la región Ceres, así como en las transformaciones habidas en el paisaje de esa región. Para ello, fueron necesarias etapas metodológicas de carácter teórico-conceptual; realización de trabajos de campo en los municipios de la microrregión de Ceres, para la observación y para hacer entrevistas a los principales actores sociales involucrados; tabulaciones, mapeos y análisis de los datos reunidos. Se pudo observar con esa investigación que las formas espaciales establecidas por la actividad de la caña de azúcar, así como los efectos, las desigualdades y los conflictos, se materializan en el paisaje regional, el cual se alteró rápidamente en la microrregión de Ceres, con la expansión del capital cañero posterior al proyecto de las Colonias Agrícolas Nacionales.

Palabras clave: Actividad cañera, Colonias Agrícolas Nacionales, paisaje regional.

Introdução

A atividade canavieira conjuga produção, processamento e circulação dos produtos, por meio de um sistema agroindustrial bastante complexo. Essa atividade acaba por influenciar e dinamizar o campo e a cidade, o rural e o urbano, bem como a região a qual está inserida. Diante disso, buscou-se aqui utilizar a abordagem regional para compreender as problemáticas, fruto da lógica do capital canavieiro, pois acredita-se que estas perpassam os limites municipais, influenciando direta e indiretamente as dinâmicas socioeconômicas estabelecidas e os efeitos materializados.

Faz-se importante resgatar, de forma sintética, os principais contextos relacionados à expansão da atividade canavieira no Brasil. Durante o período colonial brasileiro, o desenvolvimento da economia variou de acordo com os interesses e as oscilações da metrópole Portuguesa e do mercado internacional da época. Assim, durante o período colonial, podem-se destacar três produtos ${ }^{1}$ : primeiro, o Pau-Brasil, seguido pelo açúcar e a mineração, sobretudo a extração do ouro. Durante esse período, cada um deles experimentou o seu momento de expansão e a sua fase de decadência, sendo que foi durante a República Oligárquica (1889-1930) que se verificou o auge e a decadência da atividade canavieira. 
Nos anos 1930 foi criado o Instituto do Açúcar e do Álcool no Brasil (IAA) e a intervenção estatal dominou praticamente toda a estrutura do setor, sendo responsável pelo ciclo de produção e comercialização, inclusive fixação de preços, cotas, exportação e importação (Unica, 2007). Segundo Andrade (1994), o IAA passou a controlar o preço do açúcar e a cobrar taxas que equilibrassem a economia açucareira de várias regiões. Mas, foi no período pós-guerra, com a introdução de máquinas na agricultura, por meio da importação de tratores, de elementos químicos, como fertilizantes e defensivos agrícolas, e mudanças de ferramentas e de culturas ou incorporação de novas variedades de insumos, que as agroindústrias, de modo geral, desenvolveram-se ${ }^{2}$.

Somado a esse contexto, destacam-se dois momentos fundamentais para o estímulo à produção canavieira no Brasil: primeiramente, a crise mundial do açúcar e, logo em seguida, as sucessivas crises mundiais do petróleo (em 1975 e 1979); e a criação no Brasil do Programa Nacional do Álcool (Proálcool ${ }^{3}$ ). Em decorrência desse contexto mundial a autossuficiência energética foi amplamente estimulada no Brasil (por ser um elemento geopolítico de suma importância), sobretudo pelos Planos Nacionais de Desenvolvimento (PND's) durante o Regime Militar. Diante disso, houve durante essa década, a intensificação da expansão canavieira e a territorialização de destilarias e/ou usinas ${ }^{4}$ em todo território nacional.

Além do Proálcool, um contexto mais recente merece atenção. Em meados dos anos 2000 houve um verdadeiro boom canavieiro, associado inicialmente à crise global de energia, com a crescente preocupação ambiental que propunha a produção de combustíveis alternativos à gasolina (principalmente após o Protocolo de Kyoto), o que culminou com o crescimento do uso de biocombustíveis (como o etanol) e de biodiesel, amparados no Brasil, pelo Plano Nacional de Agroenergia (2006-2011).

A partir do ano 2006, observou-se um incremento notável das áreas plantadas com cana-de-açúcar, do número de usinas em funcionamento e em processo de implantação e o desenvolvimento de políticas federais e estaduais importantes para o setor, já que despontava como maior produtor mundial de etanol derivado da cana-de-açúcar. Os estados de São Paulo (maior produtor nacional), Minas Gerais, Goiás e Mato Grosso do Sul são os que apresentavam maior expansão em área plantada de cana e instalação de empreendimentos. Destaca-se que, após essa ascensão, o setor vem enfrentando novamente crises, com o fechamento de algumas 
usinas. De acordo com a União Nacional da Indústria de Cana-de-açúcar (Unica, 2013), mais de 40 usinas deixaram de funcionar, entre 2008 e 2012, sendo 30 delas apenas entre 2011 e 2012.

O presente texto possui como recorte espacial a microrregião Ceres, Goiás, e como principal recorte temporal a partir da década de 1940, que corresponde ao principal contexto de formação territorial dessa região, relacionado ao projeto das Colônias Agrícolas Nacionais (CANG), durante a Marcha para o Oeste, no Governo Vargas. Entende-se assim, a importância de se considerar o recorte: das Colônias Agrícolas Nacionais ao momento atual, não somente pelo contexto de criação, consolidação e fragmentação municipal dessa região estarem diretamente associados a esse contexto, mas também por representar duas temporalidades distintas na região: a CANG, enquanto estratégia de ocupação baseada na doação de lotes para a produção familiar, e o momento atual, tão imerso na lógica do agronegócio sucroenergético.

Objetiva-se, em síntese, compreender a territorialização canavieira no estado de Goiás, com verticalização para a microrregião Ceres, bem como as transformações ocorridas na paisagem regional dessa microrregião, sobretudo a partir das Colônias Agrícolas Nacionais ao momento atual, vinculado à expansão sucroenergética e monopolização do capital agroindustrial.

Para o desenvolvimento da proposta, foram necessárias algumas etapas metodológicas, que podem ser sintetizadas em três grandes etapas: 1) Levantamento teórico, metodológico e conceitual, e levantamento de dados primários e secundários (em órgãos e instituições públicas e privadas relacionadas à temática da pesquisa); 2) Realização de trabalhos de campo aos municípios da microrregião Ceres, sobretudo aos municípios que contêm usinas implantadas e municípios vizinhos a estes, para observação e entrevistas aos principais atores sociais envolvidos (secretários de agricultura e diretores agrícolas, além de entrevistas às usinas). Foram realizados quatro trabalhos de campo ${ }^{5}$, sendo: um em julho de 2014, aos municípios de Ceres e Carmo do Rio Verde; um em dezembro de 2015, aos municípios de Nova Glória, Santa Isabel e São Luiz do Norte; e dois trabalhos de campo no mês de maio de 2016, para os municípios de Goianésia, Carmo do Rio Verde, Itapuranga, Itapaci e Rubiataba; 3) E por fim, tabulação dos dados levantados (prévios e de campo), elaboração 
de mapas, utilizando-se do SIG ArcGIS, análises das informações obtidas em campo e escrita de textos parciais e finais.

A paisagem regional na microrregião Ceres - da CANG ao agronegócio canavieiro

\section{A Colônia Agrícola Nacional - CANG}

Dentro da Marcha para o Oeste, foi criado o projeto das Colônias Agrícolas Nacionais (CANG), também pensado como uma estratégia de ocupação do interior do Brasil, por meio de colônias agrícolas. A primeira colônia agrícola do Brasil foi implantada na região conhecida na época como Mato Grosso Goiano, onde hoje está localizado o município de Ceres, no estado de Goiás.

A base da ocupação do Mato Grosso Goiano deu-se pelas migrações, relacionadas ao processo de colonização da CANG6 ${ }^{6}$ Segundo Faissol (1952) a migração estava sendo realizada em uma escala nunca vista em Goiás até o momento. A maior parte dos migrantes era constituída por mineiros (das cidades de: Patos de Minas, Abaeté, Carmo da Paranaíba e outros municípios do oeste de Minas Gerais), mas também havia um número considerável de paulistas, baianos, maranhenses e mesmo goianos, de outras localidades do Estado. Segundo Estevam (1997, p. 91) "na verdade, tratava-se de pessoas sem recursos, na maioria agregados de fazendas, meeiros e arrendatários, que marchavam em busca da terra prometida”.

A colônia foi gradativamente apresentando incremento populacional, por meio das migrações, sendo que no ano de 1946 já contava com 1.600 famílias implantadas. No ano de 1950 a população era de quase $30 \mathrm{mil}$ pessoas, o que conferia à colônia uma densidade demográfica de 35 hab/ $\mathrm{Km}^{2}$. Grande parte das famílias habitavam a zona rural, que nessa época tinha aproximandamente 93\% da população (Aranha, 2001).

A paisagem regional nessa época estava voltada para a produção de alimentos, principalmente arroz, feijão, abóbora, milho, etc., e os trabalhadores eram os moradores, junto às suas famílias, da colônia agrícola (Figura 1). 


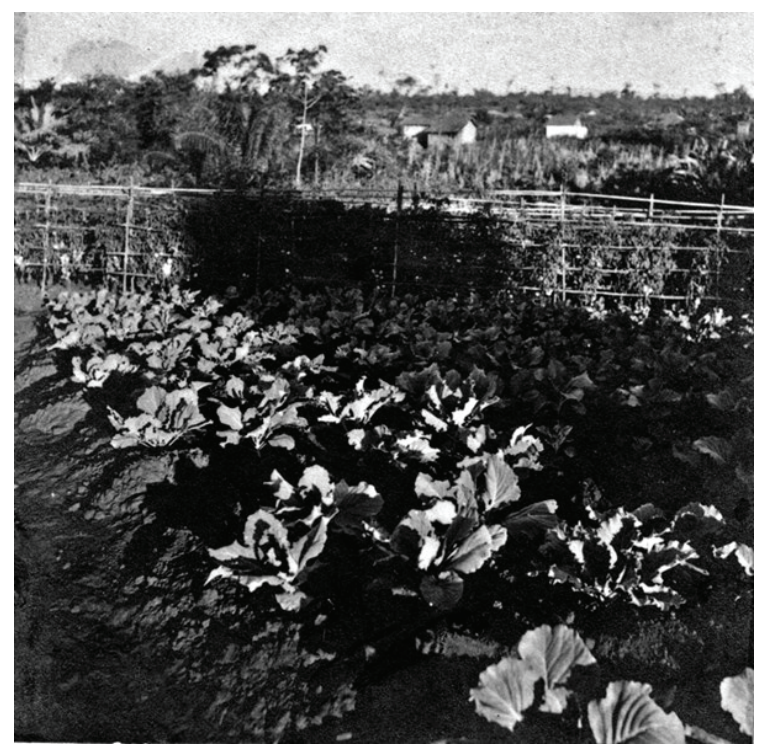

Figura 1 - Plantio de hortaliças na Colônia Agrícola - CANG, década de 1940

Fonte: IBGE cidades, 2016.

Segundo Castilho (2012), a marcha em direção à CANG significou mais que uma aventura, uma ampliação econômica do território nacional e a ligação com o mercado consumidor de São Paulo, por exemplo. Além da expansão do comando federal, o projeto de modernização da agricultura na região estudada significou também a criação de demanda para a indústria paulista.

Com o passar do tempo, a falta de investimento e a insuficiência das políticas de apoio ao pequeno produtor, além da infraestrutura local e regional incipiente, foram fatores que levaram ao gradativo esvaziamento da colônia. A emancipação da colônia aconteceu no ano de 1953 e foi desmembrada das terras do município de Goiás, por meio da Lei $\mathrm{n}^{0} 767$, e recebeu o nome de "Ceres" pelo administrador da colônia, Bernardo Sayão, em homenagem a deusa da agricultura e dos cereais (Mitologia Romana). 
O agronegócio ${ }^{7}$ canavieiro possui produção agrícola altamente tecnificada, com a presença de insumos, implementos agrícolas, maquinários altamente modernos, além do processamento industrial da cana, com a produção, em suas várias formas, de açúcar (VHP, cristal, refinado K, orgânica), etanol (anidro, hidratado, em gel), energia (pela biomassa da cana: bagaço e palha), levedura, etc. Além de todas as relações que se antecipam e que finalizam esse sistema, como as relações de circulação, transporte, logística, fomentos, mercado e consumo, enfim, as relações capitalistas e de poder envolvidas nesse processo.

A expansão canavieira para o estado de Goiás teve seu primeiro marco durante a década de 1970, com os incentivos do Proálcool algumas destilarias foram implantadas no Estado, dando início à territorialização da cana-de-açúcar em Goiás. Contudo, foi em meados dos anos 2000 que houve um verdadeiro boom canavieiro no Estado, fruto do Plano Nacional de Agroenergia e do contexto nacional e internacional da bioenergia. $\mathrm{dN}$ ano de 2005 havia 14 usinas em operação em Goiás, com uma produção de 15.642.125 toneladas (t) de cana-de-açúcar. No ano de 2007, havia 18 usinas em operação e aproximadamente 30 usinas em processo de avaliação. O estado de Goiás possui posição geográfica estratégica, razoável infraestrutura implantada e terras mais baratas se comparado ao estado de São Paulo (maior produtor de cana do Brasil), além de possuir, em sua maioria, solos e clima favorável ao cultivo de cana, além de uma área extensa do território goiano estar em áreas de chapadas, o que facilita a inserção de maquinários para plantio e colheita da cana-de-açúcar.

Algumas usinas propostas tiveram o pedido negado para implantação, contudo a maioria foi aprovada, mas não foram implantadas devido a questões de cunho financeiro, sobretudo, à crise econômica de $2008^{8}$. Portanto, atualmente, segundo os dados do Instituto Mauro Borges, da Secretaria de Estado de Gestão e Planejamento de Goiás (IMB, 2016), existem 37 usinas sucroenergéticas implantadas e em funcionamento em Goiás, duas usinas com a licença suspensa temporariamente, quatro usinas em processo de implantação e dez usinas em provável implantação.

A Tabela 1 mostra os dados de produção canavieira, etanol e açúcar para Goiás, entre os anos 2005 a 2015. Por meio da observação dos dados, verifica-se que a quantidade de usinas mais que dobrou no período avaliado e a produção de cana, assim como a de etanol e açúcar, cresceu consideravelmente ao longo do tempo, salvo algumas pequenas oscilações. Destaca-se também que a área plantada com cana-de-açúcar 
vem crescendo ao longo do tempo, o que refuta a afirmação do setor no que se refere a não incorporação de novas áreas para o plantio de cana, mas sim um alto investimento na produtividade, o que aumentaria a produção, mas manteria a área plantada. Conforme verificado nos dados, a área plantada aumentou substancialmente.

Tabela 1 - Destilarias em operação e produção de cana-de-açúcar, etanol e açúcar - 2005-2015, no estado de Goiás

\begin{tabular}{c|c|c|c|c|c}
\hline Ano & $\begin{array}{c}\text { Destilarias/ } \\
\text { Usinas }\end{array}$ & $\begin{array}{c}\text { Produção - } \\
\text { Cana-de- } \\
\text { açúcar (t) }\end{array}$ & $\begin{array}{c}\text { Área Plantada } \\
\text { - Cana-de- } \\
\text { açúcar (ha) }\end{array}$ & $\begin{array}{c}\text { Etanol } \\
\text { (mil litros) }\end{array}$ & $\begin{array}{c}\text { Açúcar } \\
\text { (t) }\end{array}$ \\
\hline 2005 & 14 & 15.642 .125 & 196.596 & 728.979 & 749.838 \\
\hline 2006 & 15 & 19.049 .550 & 232.577 & 821.616 & 766.322 \\
\hline 2007 & 18 & 22.063 .677 & 273.870 & 1.213 .733 & 952.312 \\
\hline 2008 & 28 & 33.041 .559 & 404.670 & 1.922 .414 & 1.247 .039 \\
\hline 2009 & 35 & 43.666 .585 & 518.768 & 2.196 .179 & 1.384 .081 \\
\hline 2010 & 36 & 47.733 .283 & 578.666 & 2.895 .998 & 1.798 .457 \\
\hline 2011 & 34 & 54.903 .085 & 697.541 & 2.675 .292 & 1.752 .398 \\
\hline 2012 & 37 & 53.915 .572 & 732.870 & 3.130 .577 & 1.875 .260 \\
\hline 2013 & 37 & 69.376 .714 & 860.482 & 3.887 .830 & 1.890 .648 \\
\hline 2014 & 37 & 70.152 .466 & 894.843 & 4.226 .854 & 1.997 .114 \\
\hline
\end{tabular}

Fonte: IBM (2016).

A maioria das usinas implantadas em Goiás está geograficamente instalada em um eixo centro norte-sul-sudoeste do Estado, como pode ser observado na Figura 2. Esta lógica de espacialização também está associada à malha viária implantada nesse eixo, com destaque para a BR-153 que corta o estado de Goiás, de norte a sul, o que facilita logística e financeiramente o escoamento e a circulação da produção.

Na Figura 2 há em destaque duas áreas pontilhadas, as quais representam, em azul, a microrregião sudoeste do estado de Goiás e, em vermelho, a microrregião de Ceres. O sudoeste goiano é sem dúvida, a região goiana que apresenta maior dinamismo econômico relacionado ao agronegócio, principalmente, com a produção de grãos e proteína animal e, mais recentemente, cana-de-açúcar. No sudoeste goiano há visivelmente uma disputa pela terra entre as culturas e também com as 
áreas de pastagens, pode-se exemplificar com o caso do município de Quirinópolis, onde a área de produção canavieira aumentou 650\% entre os anos de 2006 e 2009, na medida em que o cultivo de arroz declinou 70\% e da soja 16\%, como bem explicitou Arrais (2013).

A microrregião Ceres também se destaca na produção canavieira. Essa região, diferente do sudoeste goiano, já possui usinas implantadas desde o final da década de 1960, a primeira usina de produção de açúcar implantada na região foi no município de Goianésia, no ano de 1969.

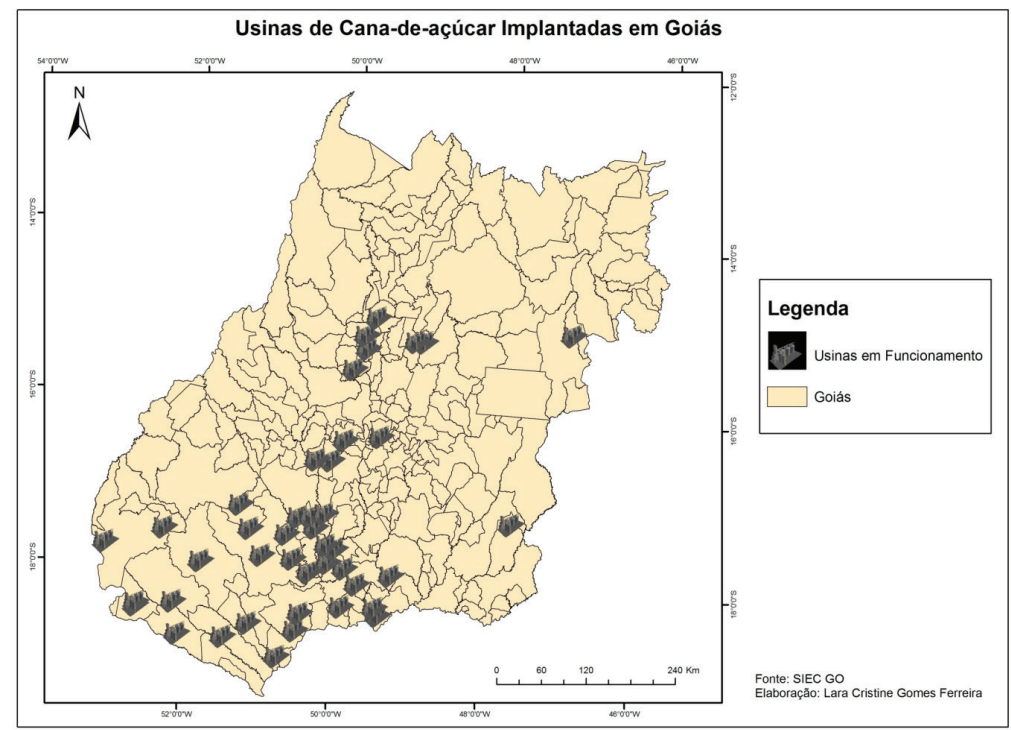

Figura 2 - Mapa da espacialização das usinas sucroalcooleiras de Goiás Fonte: IBM (2013).

São sete usinas implantadas na microrregião Ceres, nos municípios de Rubiataba, Itapaci, Itapuranga, Carmo do Rio Verde e Goianésia, sendo que neste último há três usinas em funcionamento (Figura 3). Essa região, ao contrário do sudoeste do estado, possui topografia acidentada o que dificulta a inserção total da mecanização da colheita da cana, o que traz para o município e região sérias problemáticas socioespaciais, bem como disputas e conflitos, que são visíveis na paisagem regional.

As figuras 4 e 5 mostram a espacialização da produção canavieira, em toneladas, na microrregião Ceres, para o ano 2000 (anterior ao Plano 


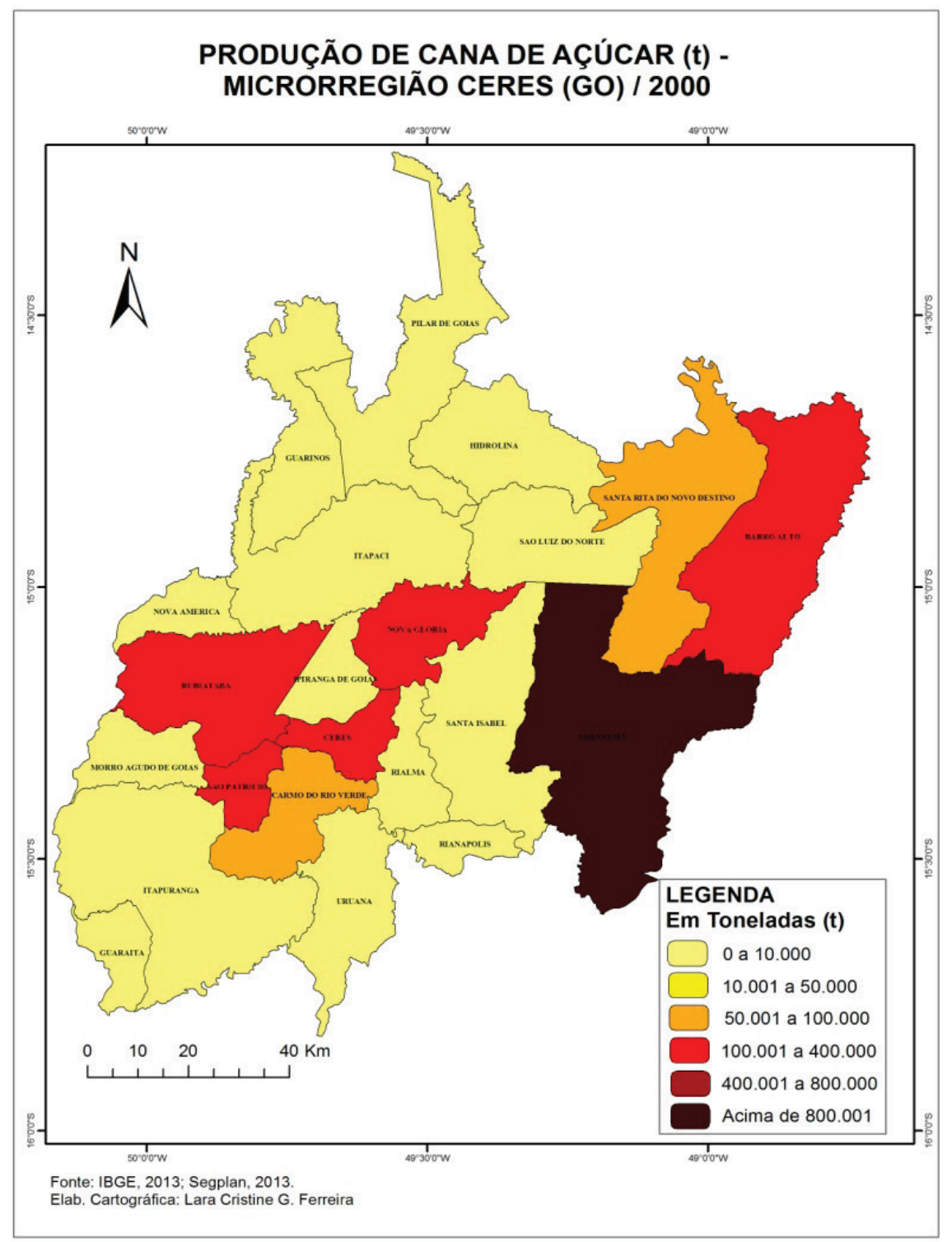

Figura 4 - Produção canavieira - microrregião Ceres, 2000. 


\section{PRODUÇÃO DE CANA DE AÇÚCAR (t) - MICRORREGIÃO CERES (GO) / 2015}

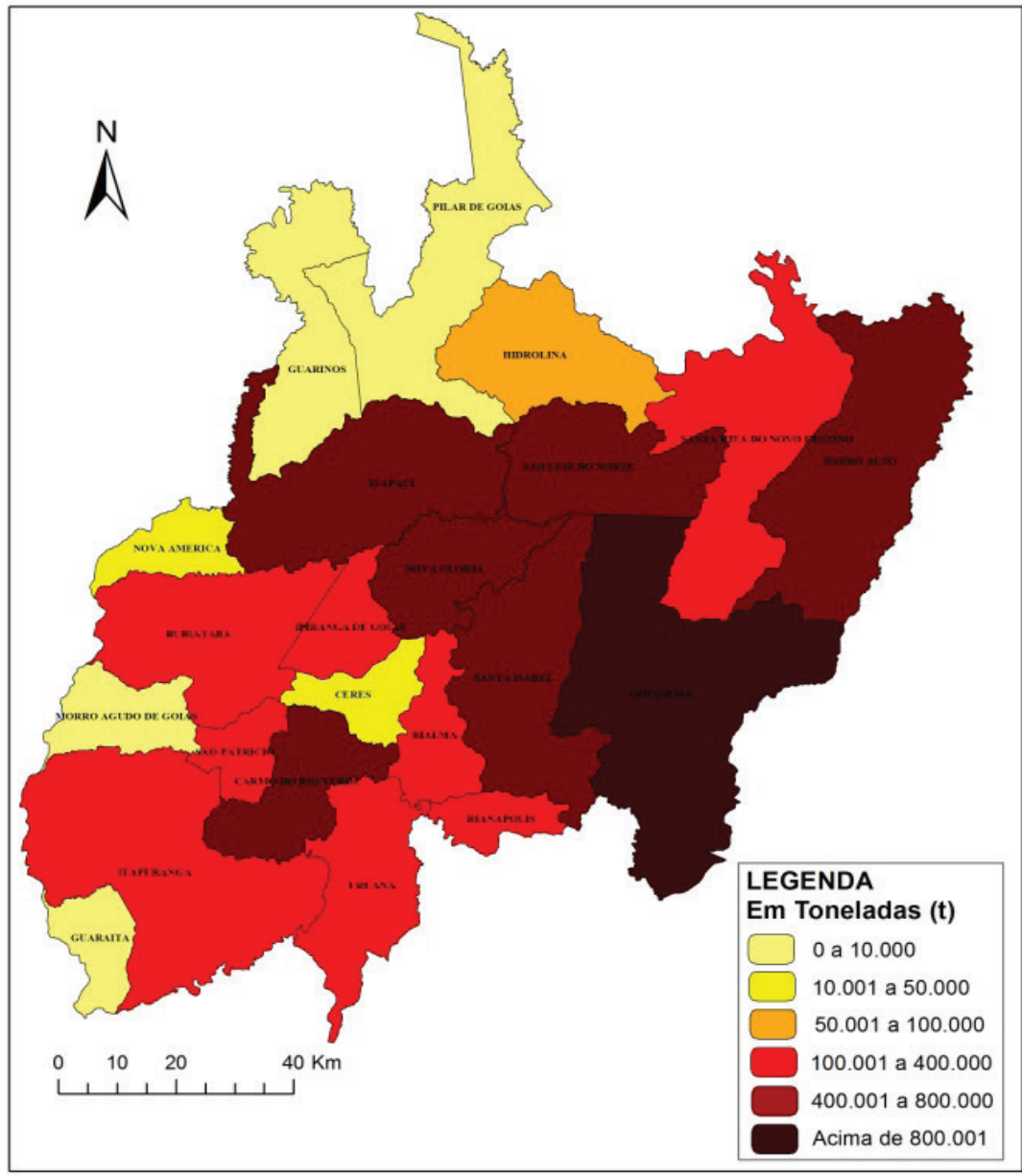

Fonte: IBGE, 2015; Segplan, 2016.

Elab. Cartográfica: Lara Cristine G. Ferreira

Figura 5 - Produção canavieira - Microrregião Ceres, 2015.

Fonte: Lara Cristine Gomes Ferreira (2016) 


\section{A paisagem regional}

para Santos (1985), a paisagem é como um palimpsesto que resulta de acumulações, nas quais algumas construções permanecem intactas ou modificadas, enquanto outras desaparecem para ceder lugar a novas edificações. Assim, a paisagem revela um mosaico de relações, formas, funções e sentidos.

Outros importantes autores trazem concepções de paisagem que complementam seu entendimento. Para Corrêa (2000), as desigualdades que aparecem, caracterizam-se pela combinação de aspectos distintos dos diversos momentos históricos, o que acaba por imprimir marcas na paisagem, que nada mais são que uma expressão dos modos de vida humanos. Corrêa (2014) também discute que a paisagem é constituída por um conjunto articulado de formas materiais que podem ser criadas tanto pela natureza quanto pela ação humana, atribuindo funcionalidades e impregnando significados.

Para Naranjo (2002), a paisagem contém materializadas, distintas soluções que as distintas gerações (em diferentes condições técnicas), têm dado à ocupação e ao uso de um território. As transformações técnicas, políticas, econômicas e sociais vêm crescendo, principalmente após o século XVI, e vêm alterando o sentido da paisagem, introduzindo um valor de troca e novos signos e sentidos (Corrêa, 2014).

A sociedade capitalista, sobretudo nas últimas décadas, na ânsia de progresso somado à capacidade tecnológica, que vem evoluindo sobremaneira ao longo do tempo, modifica a natureza cada vez mais rapidamente, incorporando arranjos e estruturas artificiais discordantes com a paisagem, e muitas vezes numa velocidade tão grande que a própria sociedade tem dificuldade em assimilar.

Essas novas transformações e possibilidades modificaram radicalmente a relação entre o ser humano e a natureza, de modo que o ser humano passa a ser o agente transformador e a construir, muito rapidamente, uma segunda natureza, cada vez mais artificializada e com um grande número de fixos artificiais (Santos, 2002).

A paisagem concede personalidade ao espaço, considerando como uma totalidade que resulta da combinação de múltiplos elementos, físicos e humanos, além de uma trajetória histórica (Rodriguez, 2006). E é essa personalidade, concedida pela paisagem ao espaço, que revela os efeitos 
e os conflitos acumulados ao logo do tempo. Assim, quando se observa a paisagem não se vê somente elementos simples, como sua fisionomia, relevo ou vegetação, mas, sobretudo, como tem se dado seu uso ao logo do tempo.

Para essa noção, o que está materializado na paisagem, está carregado também de sentido político, pois o que está visível acaba por desvelar as políticas aplicadas no lugar, os agentes com interesses diversos que se inseriram, além da permissão (e estímulo) do Estado na territorialização dos empreendimentos, empresas, corporações, agronegócios, entre outros exemplos.

Concorda-se com Santos (1988), quando esse diz que a paisagem é um conjunto heterogêneo de formas naturais e artificiais e é formada por frações de ambas. Segundo esse autor, quanto mais complexa a vida social, mais distantes os sujeitos estão de um mundo natural e mais próximos a um mundo artificial. A paisagem é heterogênea porque corresponde a uma "escrita" sobre a outra, além de conter objetos e elementos materializados, com idades diferentes. Ainda para Santos (1988, p. 24), "a paisagem não é dada para todo o sempre, é objeto de mudança. É um resultado de adições e subtrações sucessivas. É uma espécie de marca da história do trabalho e das técnicas".

A esse conceito de paisagem de Milton Santos, pode-se dialogar com o conceito de rugosidades, também desse autor, o qual reflete que os conjuntos de formas espaciais ficam à espera, prontos para eventualmente exercer funções, ainda que limitadas por sua própria estrutura. Assim,

O trabalho já feito se impõe sobre o trabalho a fazer. A atual repartição territorial do trabalho repousa sobre as divisões territoriais do trabalho anteriores. E a divisão social do trabalho não pode ser explicada sem a explicação da divisão territorial do trabalho, que depende, ela própria, das formas geográficas herdadas. (Santos, 2002, p. 92)

Para analisar e compreender a paisagem é necessário também ter em mente a importância do tempo. Toda ação humana está inscrita no espaço e no tempo, incorporando e criando elementos e atributos. Além do tempo, a escala também é muito importante nessa análise, pois os objetos ganham ou perdem visibilidade ao se alterar a escala espacial. A paisagem local não exibe os mesmos objetos da paisagem regional. Segundo Corrêa (2014), com a escolha da escala, a problemática e os questionamentos 
podem variar, além de que os processos que atuam na escala regional podem ser mais amplos que na escala local, por exemplo.

Desta forma, quando um empreendimento se instala em determinada região, acaba por criar uma organização espacial própria, mas também se relaciona com uma organização previamente existente. $\mathrm{O}$ empreendimento pode alterar parcialmente a realidade regional e isso pode ser verificado por meio de sua paisagem.

Com a intensificação do processo de globalização, o conceito de região passou a ser questionado, sobretudo porque alguns autores entendiam que a globalização seria responsável por uma homogeneização espacial. Nessa discussão sobre globalização e região, dois pontos merecem destaque: primeiro, a ideia do seu potencial homogeneizador, pois no mundo globalizado não haveria espaço para a diferenciação e isso aconteceria também com a região, já que essa guarda em sua essência, a noção de singularidade. O segundo ponto está centrado no discurso que prega o fim do "Estado-Nação", pois tem-se de um lado, a emergência de uma cultura global e, de outro, uma economia também global (Arrais, 2007).

Concorda-se com Pontes (2007), a qual defende que a globalização pode não significar homogeneização total, mas sim diferenciação das partes, isso ocorre devido as diferentes potencialidades regionais e dos vários agentes que atuam com forças desiguais no território. Para Haesbaert e Limonad (2007, p. 40),

Se muitos autores afirmam que o mundo contemporâneo vive uma era de globalização, outros, por sua vez, enfatizam como característica principal do nosso tempo a fragmentação. Globalização e fragmentação constituem de fato os dois pólos de uma mesma questão que vem sendo aprofundada, seja através de uma linha de argumentação que tende a privilegiar os aspectos econômicos - e que enfatiza os processos de globalização inerentes ao capitalismo, seja através do realce de processos fragmentadores de ordem cultural.

Para Elias e Pequeno (2007) a reestruturação do agronegócio e da agropecuária não homogeneizou a produção ou os espaços agrícolas nem os espaços urbanos que cresceram com este processo. O que de fato acontece é um intenso processo de fragmentação da produção e do espaço agrícola, em contraposição ao processo de globalização da produção e do consumo agropecuário. 
Assim, entendendo a paisagem e a região como categorias fundamentais para a leitura e compreensão dos processos ocorridos ao longo do tempo e da realidade atual da microrregião Ceres, propõe-se pensar na noção de paisagem regional, que não seria somente a junção dessas duas importantes categorias, mas uma forma mais ampla e complexa de verificar ao mesmo tempo as problemáticas postas pela dinâmica sucroenergética e as diferenciações que esse processo acarreta na região e que se apresenta visível por meio de sua paisagem.

Desta forma, entende-se paisagem e região como conjuntos heterogêneos, sobretudo quando se considera a intensificação da globalização, que atua de diferentes formas. Na região estudada pode-se destacar a reestruturação produtiva, a inserção de técnicas modernizantes, bem como a atuação de distintos agentes, que contribuem para diferentes construções socioespaciais.

Além de serem conjuntos heterogêneos, entende-se que paisagem e região podem ser conceitos complementares, já que um auxilia na compreensão do outro. Oliveira (1981) já apontava que as diversas formas de reprodução do capital, conformaria "regiões" distintas e que algumas regiões seriam hegemonicamente controladas pelos setores mais avançados da produção capitalista. Os produtos e as formas, consequências das diferentes ações e atuações dos agentes do capital sobre as regiões, estão materializados na paisagem regional.

A paisagem regional está diretamente relacionada ao contexto histórico que se vive. Em temporalidades distintas, têm-se paisagens regionais também distintas. E em uma mesma região tem-se paisagens muito parecidas, fruto de processos e formas semelhantes e, ao mesmo tempo, podem-se ter paisagens diferentes, já que a produção capitalista se realiza de modo diferente nos lugares, além de algumas rugosidades presentes. Assim, a análise da microrregião Ceres contribuiu para compreender essas afirmações.

A paisagem regional, que durante a CANG, era voltada para a diversidade em produção de alimentos, técnicas mais simples de produção e famílias envolvidas no plantio, colheita e comercialização nas feiras locais; hoje predomina as extensas lavouras de cana-de-açúcar, modernas máquinas para a colheita mecanizada e ainda a presença de trabalhadores cortadores de cana. A Figura 6 mostra um exemplo recorrente na paisagem canavieira na microrregião Ceres: a constante presença das lavouras 
canavieiras nas rodovias e estradas vicinais, bem como no perímetro urbano de algumas cidades.

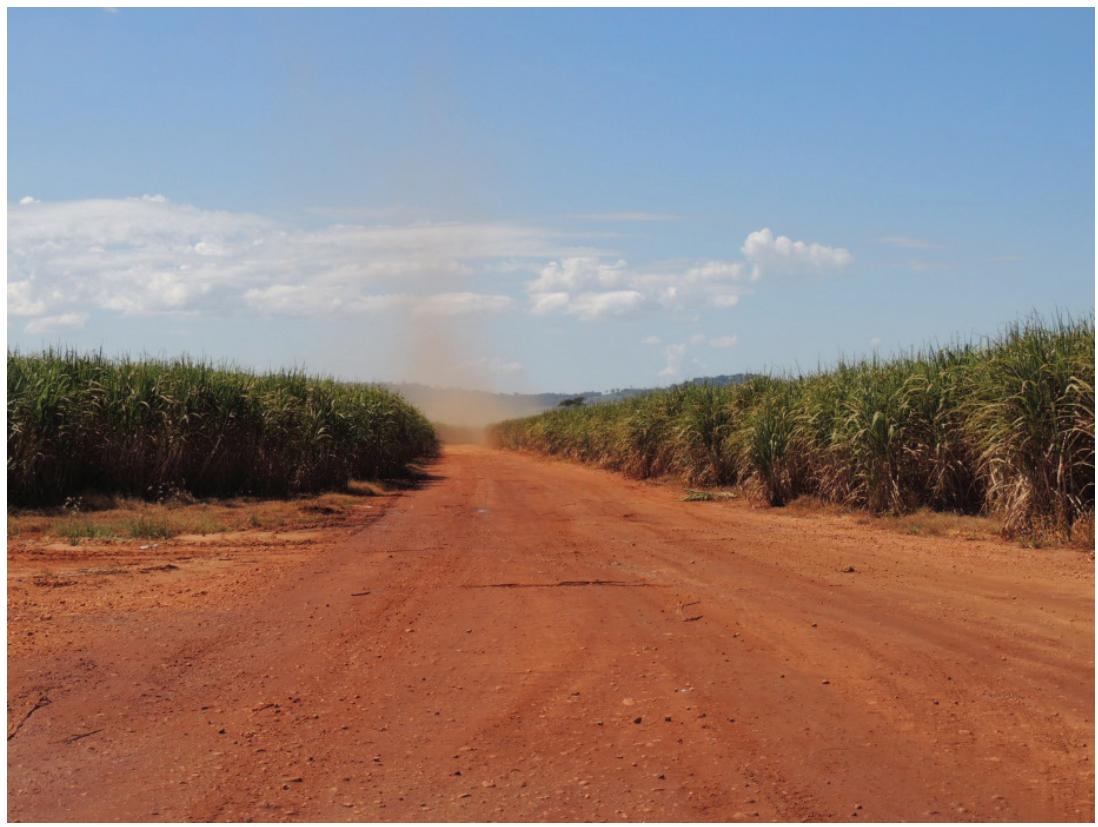

Figura 6 - Lavoura de cana-de-açúcar na Microrregião Ceres

Fonte: Elaborada pela autora, maio de 2016.

Verifica-se também na paisagem regional uma intensa alteração nas técnicas de produção, principalmente quando se observa o recorte temporal da pesquisa. Durante a CANG as técnicas agrícolas eram mais rudimentares e o trabalho era, em grande parte, manual, com o envolvimento de toda a família, portanto, com pouca relação assalariada.

Segundo Elias e Pequeno (2007), com o processo de globalização e a intensa capitalização na agricultura há relevante reestruturação da produção e do território preexistentes, o que acaba por desorganizar as estruturas, as funções e as formas antigas. Diante disso, quando há alguma refuncionalização ou reestruturação do território para atender à produção globalizada, superpõem-se novos fixos artificiais, aumentando a complexidade dos seus sistemas técnicos e de suas rugosidades (Elias; Pequeno, 2007). 
Na microrregião Ceres, como ainda existe a colheita manual da cana-de-açúcar é muito comum verificar na paisagem regional, tanto os maquinários quanto os cortadores de cana, seja durante o corte nas lavouras mais próximas às rodovias e ao perímetro urbano, ou durante o deslocamento dos trabalhadores para as lavouras, por meio dos ônibus de transporte que saem das cidades.

Como se utiliza aqui de um dos conceitos de paisagem formulados por Milton Santos (2002), no qual a paisagem é como um palimpsesto, ou seja, resulta de acumulações e revela um mosaico de relações e formas, faz-se importante mencionar que a paisagem regional atual da microrregião Ceres, revela elementos, formas, sentidos, relacionados predominantemente com a atividade sucroenergética. A paisagem regional, atrelada ao período das colônias agrícolas, está quase que totalmente suprimida pelas paisagens da cana.

Para compreender como eram as paisagens durante a CANG, foi necessário remeter a alguns textos do Geógrafo Alemão Léo Waibel, que esteve no Brasil durante os anos 1940 e escreveu vários textos na Revista Brasileira de Geografia do IBGE. Parte de seus estudos estava relacionados à ocupação do planaldo central brasileiro, bem como trabalhava as paisagens do "mato grosso de goiano" e descrevia as formas e atividades provindas da intensa migração causada pela CANG.

Segundo Waibel (1948), a paisagem da CANG era formada por uma vegetação característica de florestas, por isso chamaram a região de Mato Grosso de Goiás. Durante a estação seca era comum o fogo nas matas, de acordo com as "informações do Dr. Sayão, diretor da Colônia Agrícola Nacional, o fogo invade até as partes mais remotas dessas florestas, destrói a vegetação original e causa uma mata secundária, rica em bambus altos, muito semelhante à que cresce nas roças abandonadas" (Waibel, 1948, p 11). A Figura 7 mostra a vegetação existente na área da CANG na década de 1940. 


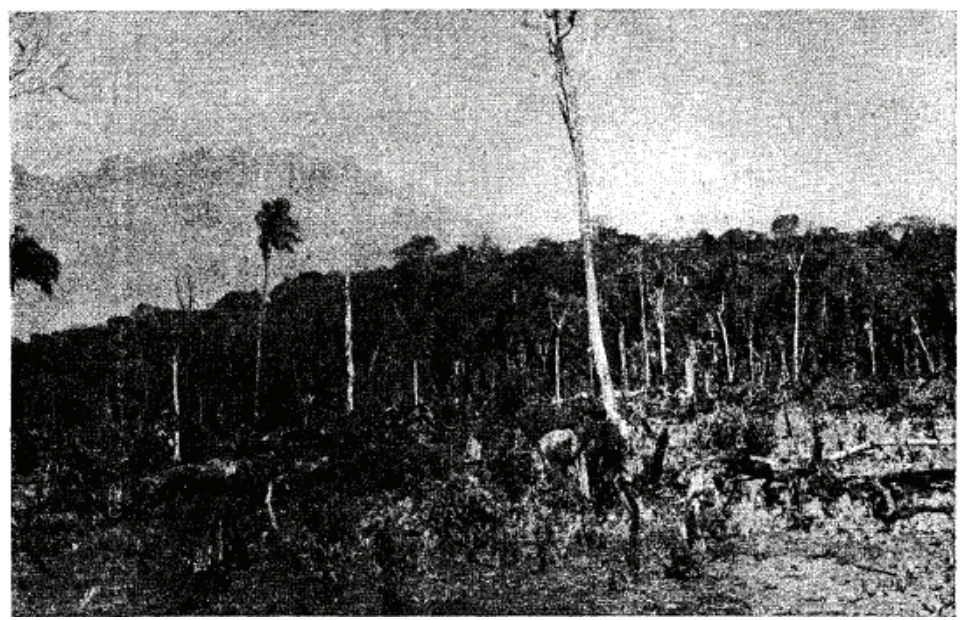

Figura 7 - Vegetação típica do "mato grosso de Goiás" durante a década de 1940

Fonte: Waibel (1948).

Nesse artigo da Revista do IBGE, Waibel ainda relatou que a atual região de Ceres não tinha agricultura bem sucedida, indicando que,

A agricultura em terras de cerrado, caso seja bem sucedida, mudará por completo a situação social e econômica do Planalto Central. Tornar-se-ia, entretanto, necessária uma mudança total dos métodos agrícolas, uma mudança da agricultura nômade para a permanente, da cultura de enxada para a cultura de arado e da rotação de terras para a rotação de culturas (Waibel, 1948, p. 32).

A leitura dos artigos de Léo Waibel contribue para ratificar o quão diferente se tornou a paisagem da microrregião Ceres ao longo dos contextos estudados e como as formas e os elementos materializados hoje na paisagem estão muito vinculados à lógica da agricultura capitalista. A Figura 8 mostra um exemplo de um elemento da paisagem que introduz ao morador, visitante ou pesquisador a lógica socioeconômica da região: uma placa na rodovia (assinada pelas usinas Cooper Rubi e CRV Industrial), muito comum ao logo das estradas da microrregião Ceres, sinalizando o intenso tráfego de treminhões nos próximos quase $50 \mathrm{~km}$ de pista.

Assim, diante da pesquisa realizada, com grande importância e destaque para os trabalhos de campo, que muito contribuíram para a 
análise da paisagem, foi possível pensar no delineamento do conceito de paisagem regional, fundamental para a compreensão da microrregião Ceres, frente à dinâmica sucroenergética e a lógica do agronegócio canavieiro, que ao longo de aproximadamente 60 anos, das Colônias Agrícolas Nacionais ao agronegócio canavieiro, praticamente dominam a região estudada.

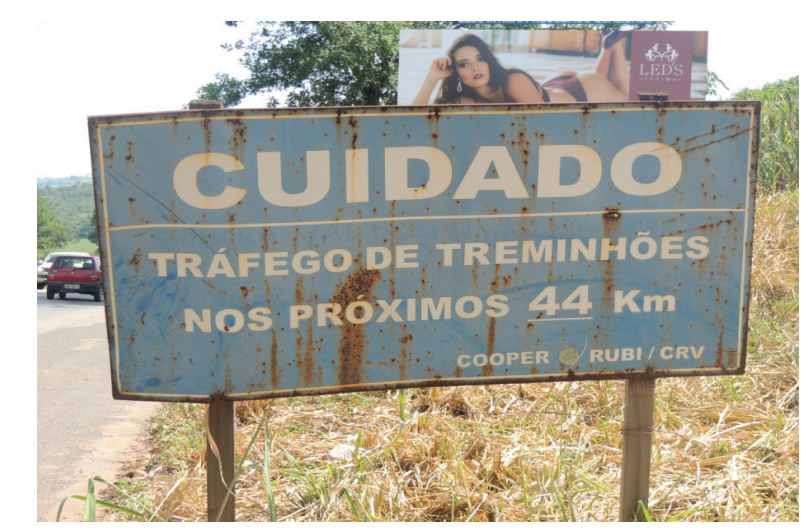

Figura 8 - Placa na rodovia indicando o intenso tráfego de treminhões entre os municípios de Rubiataba e Carmo do Rio Verde Fonte: Elaborada pela autora, maio de 2016.

Ressalta-se a importância da paisagem regional para se compreender e desvelar as contradições existentes em determinada região, bem como a incipiente discussão existente dentro desse conceito nas pesquisas brasileiras, assim, intenta-se contribuir com o delineamento desse conceito. Diante disso, entende-se aqui como paisagem regional: o conjunto visível de formas, elementos fixos, artificiais e relacionais (redes comerciais e relações de trabalho) materializados na paisagem de determinada região, fruto da atuação conjunta do capital privado e do Estado.

A Figura 9 traz um mapa que representa a dífícil tentativa de sintetizar as paisagens regionais da microrregião Ceres atualmente. Por meio dele, pode-se verificar os empreendimentos sucroenergéticos implantados e em funcionamento na região, os elementos fixos visíveis, presentes na paisagem regional, além das redes criadas.

Observa-se elementos como a maciça presença de treminhões e colhedoras de cana, além das monótonas lavouras de cana-de-açúcar 
presentes na região, não só nos municípios que possuem usinas, mas também em vários municípios próximos a esses. Também é possível verificar, por meio da Figura 9, uma imagem que mostra a proximidade das casas às lavouras de cana no perímetro urbano do município de Goianésia, o que demonstra essa dinâmica sempre presente, vinculada ao setor canavieiro, tanto no campo quanto na cidade.

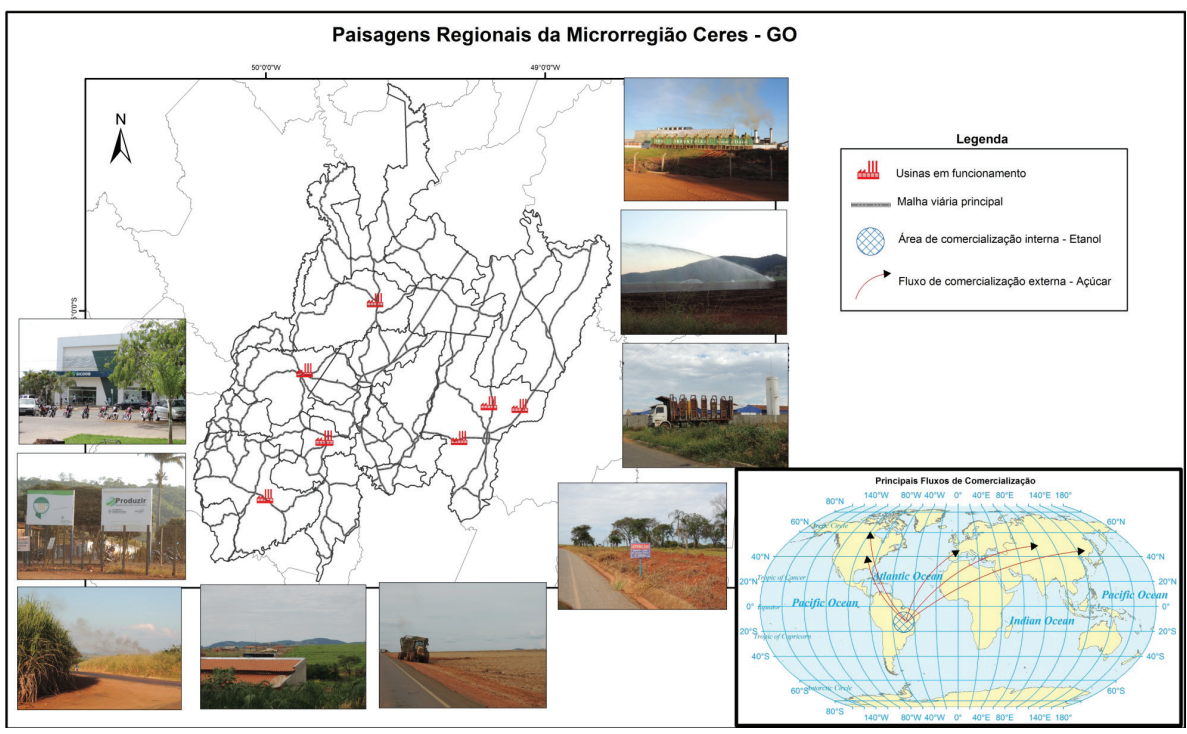

Figura 9 - Mapa síntese das Paisagens Regionais da Microrregião Ceres, Goiás - 2016

Fonte: Lara Cristine Gomes Ferreira (2016).

Várias formas e elementos fazem parte do cotidiano dos moradores das cidades canavieiras, sobretudo durante o período da safra nas usinas. Observam-se também na Figura 9, as principais malhas viárias que são fundamentais para o escoamento e circulação da produção, bem como imagens que mostram as formas presentes e materializadas nessa paisagem, destacam-se: a presença do Estado, por meio das placas dos programas de fomento à industrialização; do capital privado, com os maquinários, insumos, cooperativas de crédito; e, as redes estabelecidas, que não são visíveis na paisagem, mas que são fundamentais para a realização da lógica do agronegócio, como as redes relacionais e de comercialização, internas, 
no caso do etanol, e externas, em sua maioria, com a comercialização do açúcar, levedura e créditos carbono com vários países do hemisfério norte.

\section{Considerações finais}

A microrregião Ceres traz em sua formação histórica contextos fundamentais e que revelam problemáticas complexas, que estão materializados em sua paisagem, além de elementos e formas espaciais nítidas da principal atividade socioeconômica da região na atualidade: o agronegócio sucroenergético. Cabe aqui resgatar, que o estado de Goiás consolida-se hoje como um dos principais produtores de cana-deaçúcar do Brasil e apresenta um número relevante de empreendimentos sucroenergéticos em funcionamento.

Assim, a região foi rapidamente direcionada para a grande produção, para as monoculturas, principalmente a canavieira, já a partir do final da década de 1960 (logo após o fim da Colônia Agrícola Nacional e emancipação dos municípios). As primeiras destilarias implantadas na microrregião Ceres, estão relacionadas ao Proálcool e, a partir daí, a atividade canavieira passou a fazer parte da realidade da região. Com a introdução do Plano Nacional de Agroenergia, em 2006, vários investimentos foram realizados, o que contribuiu para a ampliação da produção sucroenergética.

A paisagem tornou-se muito importante ao longo da pesquisa, especialmente com a realização dos trabalhos de campo, onde se percebia nitidamente as formas espaciais estabelecidas pela atividade sucroenergética na região, bem como os efeitos e as desigualdades materializadas. Acredita-se que para as pesquisas que utilizem essa abordagem, partir do conceito de paisagem regional, pode ser bastante enriquecedor, pois, pode-se compreender o "conjunto visível de formas, elementos fixos, artificiais e relacionais (redes comerciais e relações de trabalho) materializados na paisagem de determinada região, fruto da atuação conjunta do capital privado e do Estado" (Ferreira 2016, p. 244), conforme se explicitou no decorrer do texto.

Ressalta-se que a paisagem regional da microrregião Ceres alterou-se muito rapidamente ao longo de quase 80 anos. Na paisagem regional, veem-se as formas espaciais e as consequências do agronegócio sucroenergético, principalmente pela região não apresentar uma 
diversificação econômica, para além da cana-de-açúcar. A microrregião Ceres se apresenta altamente concentrada e dependente das usinas implantadas, socioeconomicamente.

Essa relação trouxe claramente um desenvolvimento econômico incompleto, que é legitimado pelo mito do progresso, vinculado ao discurso do agronegócio no Brasil, o que acaba por justificar várias ações perversas desse setor na região, como os efeitos sociais e ambientais, além das contradições e desigualdades que são próprias da agricultura capitalista no Brasil e que foram fácil e perfeitamente verificadas na paisagem regional da microrregião Ceres.

\section{Notas}

1 Em Formação Econômica do Brasil, Celso Furtado, elucida como a economia Brasileira mostrava certa dependência da metrópole Portuguesa, durante o período colonial.

2 A partir de 1945 a produção brasileira de açúcar passou a crescer de forma desordenada, com o avanço da cana-de-açúcar por espaços ainda não ocupados ou ocupados por outras culturas de menor rentabilidade em relação ao mercado internacional da época (Andrade, 1994).

3 O Programa Nacional do Álcool (Proálcool) foi criado em 14 de novembro de 1975, pelo Decreto $\mathrm{n}$ - 76.593.

40 termo "destilaria" está associado à produção somente de álcool combustível, já o termo "usina" é mais amplo, designando a produção de açúcar, álcool e outros produtos.

$5 \mathrm{~A}$ escolha dos municípios para trabalho de campo esteve relacionada à localização das usinas e maiores produtores de cana-de-açúcar da microrregião.

6 A CANG foi criada pelo Decreto Lei no 6.882, de 19 de fevereiro de 1941.

7 Para Mendonça (2015, p. 397), o conceito de agronegócio "está relacionado a um conjunto de medidas impulsionadas por governos e instituições privadas que intensificaram a industrialização e a padronização da agricultura em nível internacional. Alguns dos elementos centrais deste modo de produção são a uniformidade e extensão dos cultivos, o uso de máquinas e insumos químicos, além da intensificação do uso de água e energia no processo produtivo".

8 Esse fato foi relatado inclusive pelos representantes das usinas canavieiras da microrregião Ceres durante a realização de trabalhos de campo.

\section{Referências}

ANDRADE, M. C. De. Modernização e pobreza: a expansão da agroindustria canavieira e seu impacto ecológico e social. São Paulo: Editora da Universidade Estadual Paulista - Unesp, 1994. 
ARANHA, B. da S. Eu vi Ceres nascer: A saga do bandeirante Bernardo Sayão. Goiânia: Grafia O Popular, 2001.

ARRAIS, T. A. A Produção do Território Goiano: economia, urbanização, metropolização. Goiânia: Editora UFG, 2013.

O Território Goiano: uma abordagem quase contemporânea do desenvolvimento regional. In: XII Encontro da Associação Nacional de PósGraduação e Pesquisa em Planejamento Urbano e Regional. Belém, 2007.

BRASIL. Plano Nacional de Agroenergia 2006-2011. Ministério da Agricultura, Pecuária e Abastecimento, Secretaria de Produção e Agroenergia. 2. ed. rev. Brasília: Embrapa Informação Tecnológica, 2006.

CASTILHO, D. A Colônia Agrícola Nacional de Goiás (CANG) e a Formação de Ceres-GO. Revista Élisée - UEG, Goiânia, v. 1, n. 1, p.117-139, 2012.

CORREA, R. L. Paisagem: Algumas reflexões sobre sua natureza e conexões. In: ALVES, I.; LEMOS, M.; NEGREIROS, C. (Org.). Estudos de Paisagem: Literatura, viagens e turismo cultural - BR, FR, PT. Ed. Rio de Janeiro: Oficina Raquel, 2014.

. Região e Organização Espacial. 7. ed. São Paulo: Editora Ática, 2000.

ELIAS, D; PEQUENO, R. Desigualdades Socioespaciais nas Cidades do Agronegócio. Revista Brasileira de Estudos Urbanos e Regionais, ANPUR, v. 9, n. 1, p. 25-39, 2007.

ESTEVAM, L. A. O Tempo da Transformação: Estrutura e Dinâmica da Formação Econômica de Goiás. 1997. 180 f. Tese (Doutorado em Economia) - Universidade Estadual de Campinas, Campinas, São Paulo, 1997.

FAISSOL. E. O Mato Grosso de Goiás. Rio de Janeiro: Biblioteca Geográfica Brasileira - IBGE, 1952.

FERREIRA, L. C. G. As Paisagens Regionais na Microrregião Ceres (GO) - Das Colônias Agrícolas Nacionais ao Agronegócio Sucroenergético. Tese (Doutorado em Geografia). Universidade de Brasília: Distrito Federal, 2016, p. 296

FURTADO, C. Formação Econômica do Brasil. 24 ed. São Paulo, Editora Nacional, 1991.

HAESBAERT, R.; LIMONAD, E. O Território em Tempos de Globalização. Revista etc Espaço, Tempo e Crítica, Niterói, Rio de Janeiro, v. 1, n. 2, p. 39-52, 2007.

IMB - Instituto Mauro Borges. Instituto Mauro Borges/ Secretaria de Estado de Gestão de Planejamento de Goiás. Goiás em Dados - 2012. Goiânia: SEGPLAN, 2013.

Instituto Mauro Borges/ Secretaria de Estado de Gestão de Planejamento de Goiás. Goiás em Dados - 2016. Goiânia: SEGPLAN, 2016.

MENDONÇA, M. L. O Papel da Agricultura nas Relações Internacionais e a Construção do Conceito de Agronegócio. Revista Contexto Internacional, Rio de Janeiro, v. 37, n. 2, maio/agosto 2015. 
NARANJO, F. Z. Aspectos Conceptuales, de Conocimiento Y Fundamentos Legales. In: NARANJO, F. Z.; MORENO, C. V. (Org.). Paisaje y Ordenación del Territorio. Junta de Andalucía, España: Consejería de Obras Públicas y Transportes, 2002.

OLIVEIRA, F. de. Elegia para uma re(li)gião: Sudene, Nordeste, Planejamento e Conflitos de Classe. 4. ed. Rio de Janeiro: Paz e Terra, 1981.

PONTES, B. M. S. Região e regionalização no contexto da globalização: a região sob diferentes óticas, no contexto do método dialético. Cronos, Natal, v. 8, n. 2, p. 489-499, jul./dez. 2007.

RODRIGUEZ, J. M. M. La Concepción sobre los paisajes vista desde la geografia. Boletim de Geografia, Maringá, v. 24, n. 1, p. 1-25, 2006.

SANTOS, M. Espaço e método. São Paulo: Nobel, 1985.

. Metamorfoses do Espaço Habitado: fundamentos teórico e metodológico da Geografia. São Paulo: Hucitec, 1988.

Hucitec, 2002.

. A Natureza do Espaço: técnica e tempo, razão e emoção. São Paulo:

ÚNICA. União Nacional da Indústria de Cana-de-açúcar. Produção e uso do etanol combustível no Brasil. São Paulo, 2007.

.União Nacional da Indústria de Cana-de-açúcar. Disponível em: <www. unica.com.br>. Acesso em: set. 2013.

WAIBEL, L. Vegetação e o uso da Terra no Planalto Central. Revista Brasileira de Geografia, Rio de Janeiro, Ano X, n. 3, p. 335-380, 1948.

Fernando Luiz Araujo Sobrinho - Possui graduação em Geografia, mestrado em Arquitetura e Urbanismo pela Universidade de Brasília e doutorado em Geografia pela Universidade Federal de Uberlândia. Atualmente é professor adjunto da Universidade de Brasília. ORCID: https://orcid.org/0000-0003-1815-8677.

Lara Cristine Gomes Ferreira - É Geógrafa e Mestre em Geografia pela Universidade Federal de Goiás. Doutora em Geografia pela Universidade de Brasília, com estágio doutoral na Universidade de Santiago de Compostela, Galícia / Espanha. ORCID: https://orcid.org/0000-0001-9592-7981.

\section{Contribuições dos autores}

Os autores consideram que a participação na construção da presente pesquisa foi conjunta em todas as etapas do trabalho, até a redação final do artigo. 